Check for updates

\title{
GESTÃO AMBIENTAL E CARACTERIZAÇÃO DE RESÍDUOS SÓLIDOS DE AGROINDÚSTRIAS DE PALMITO PUPUNHA DO ESTADO DO PARANÁ
}

\author{
ENVIRONMENTAL MANAGEMENT AND CARACTERIZATION OF SOLID WASTES OF PEACH PALM \\ AGROINDUSTRIES OF PARANA STATE
}

\footnotetext{
${ }^{1}$ Mestre em Sustentabilidade - Universidade Estadual de Maringá - UEM

eng.ambiental.lununes@gmail.com

${ }^{2}$ Doutora em Ciência de Alimentos - Universidade Estadual de Maringá - UEM.

beatrizbolanho@yahoo.com.br

${ }^{3}$ Doutora em Tecnologia de Fermentações Universidade Estadual de Ponta Grossa - UEPG. edgodoy@uepg.br
}

Recebido em: 19 nov. 2019

Aprovado em: 23 fev. 2020

Cite como - American Psychological Association (APA)

Santos, L. N. dos., Bolanho, B. C., \& Danesi, E. D. G. (2021, jan./mar.). Gestão ambiental e caracterização de resíduos sólidos de agroindústrias de palmito pupunha do estado do Paraná. Exacta, 19(1), 166-187.

https://doi.org/10.5585/exactaep.v19n1.16047.
Resumo: O objetivo deste trabalho foi investigar a gestão ambiental em indústrias de palmito pupunha do estado do Paraná, bem como quantificar e caracterizar seus principais resíduos. Realizou-se o levantamento de dados por meio de um questionário sobre a produção e a geração de resíduos e caracterizaram-se os principais componentes dos subprodutos. Verificou-se que são fabricados de 400 a $66.150 \mathrm{~kg} \mathrm{mês}^{-1}$ de derivados da pupunha, sendo que a cada $1 \mathrm{~kg}$ de produto são consumidos de 5,19 a 14,29 L de água e gerados de 0,86 a 8,33 L de efluente e de 4,29 a 5,72 kg de resíduos sólidos. Estes são compostos por bainhas, porção caulinar e aérea, contém altos teores de fibras $(45,53$ a 61,12 g.100 g-1) e são destinados ao meio ambiente, adubo e alimentação animal. Ampliar as práticas de produção mais limpa e o aproveitamento dos resíduos gerados são pontos importantes para garantir a sustentabilidade do setor.

Palavras-chaves: Bactris gasipaes. Gestão ambiental. Palmito. Resíduos agroindustriais.

Abstract: The aim of this work was to investigate the environmental management in the peach palm industries of the state of Paraná/Brazil, and to quantify and characterize their main residues. Data were collected using a questionnaire about the production and generation of waste and the main components of the byproducts were determined. It has been found that 400 to $66,150 \mathrm{~kg} \mathrm{month}^{-1}$ of peach palm products were produced and to each $1 \mathrm{~kg}$ of processed product 5.19 to $14.29 \mathrm{~L}$ of water is consumed and 0.86 to $8.33 \mathrm{~L}$ of effluent and 4.29 to $5.72 \mathrm{~kg}$ of solid waste were generated. The waste is composed of sheaths, stem and aerial portion, that has high fiber content ( 45.53 to $61.12 \mathrm{~g} .100 \mathrm{~g}^{-1}$ ) and they are destinate for the environment, as fertilizer and animal feed. Expanding cleaner production practices and harnessing the generated waste are important points to ensure the sustainability of the sector.

Keywords: Bactris gasipaes. Environmental management. Palm heart. Agroindustrial waste. 


\section{Introdução}

Práticas sustentáveis desenvolvidas pelas agroindústrias não devem ser mensuradas somente pela produtividade, uma vez que do início ao final da produção há uma diversidade de impactos ambientais relacionados ao elevado consumo de recursos naturais e à geração de resíduos (V. A. L. Santos \& Pierre, 2018).

Para S. P. Santos, Araújo, Morais e Vargas (2018) nos últimos anos a indústria brasileira vem procurando incorporar práticas de desenvolvimento sustentável em suas estratégias empresariais, com investimentos em eficiência energética, utilização de energia renovável, uso racional da água, minimização da geração de resíduos e desperdícios e a busca pelo reaproveitamento de materiais e produtos.

Essa tendência, antes priorizada meramente pelo setor de exportação, tem respondido de maneira positiva às pressões impostas pelas exigências de clientes corporativos e consumidores do mercado interno (Piacente, 2005). Além do mais, a fiscalização ambiental tem contribuído para a busca de um gerenciamento ambiental que atenda às exigências e responsabilidades estabelecias pelas legislações e normalizações do setor (V. A. L. Santos \& Pierre, 2018).

Diversos estudos, com indústrias do ramo alimentício, têm relatado condutas que objetivam a adoção de posturas ambientalmente responsáveis (Ferreira, Santos, Thomaz \& Rebelato, 2018; Lima, Ferreira, Vaz, Andrade \& Ferreira, 2018; Piacente, 2005). Essas posturas englobam, além da racionalização do uso de água e energia, a gestão de resíduos, uma vez que estes são produzidos em grande escala pelo setor agroindustrial (V. A. L. Santos \& Pierre, 2018). Os resíduos produzidos nesse setor são denominados "resíduos agroindustriais" e pertencem aos resíduos sólidos orgânicos, compondo-se de frações residuais das plantas (Vojvodic, Komes, Vovk, Belscakcvitanivió \& Busic, 2016) e de animais.

No Paraná, as agroindústrias de palmito pupunha (Bactris gasipaes Kunth) geram elevadas quantidades de resíduos provenientes da comercialização do produto principal. Estima-se que, de cada planta de palmito colhida, extrai-se aproximadamente $400 \mathrm{~g}$ de palmito comercial, gerando cerca de 13 kg de resíduos, incluindo estipe, folhas e bainhas, sendo que algumas delas permanecem no local da colheita (Fermino et al., 2014). Esses resíduos, se não destinados adequadamente, podem causar potenciais efeitos prejudiciais ao meio ambiente. Logo, os resíduos gerados nesses locais ocupam posições de destaque na gestão ambiental e na busca de opções de Produção Mais Limpa (PML), principalmente no que se refere ao seu reaproveitamento.

Assim, o objetivo deste trabalho foi investigar as práticas de gestão ambiental desenvolvidas pelas indústrias beneficiadoras de palmito pupunha do estado do Paraná, bem como caracterizar e quantificar os principais resíduos sólidos gerados. Os resultados obtidos nesse trabalho poderão auxiliar 
no diagnóstico da situação atual das indústrias de pupunha paranaenses. Além disso, ao se investigar as práticas de gestão ambiental realizadas e a composição dos subprodutos gerados, almeja-se entender quais são as principais necessidades do setor, visando atingir aspectos importantes para sustentabilidade.

\section{Revisão bibliográfica}

\subsection{Gestão ambiental}

A administração ambiental ou gestão ambiental consiste nas diretrizes e atividades administrativas realizadas por uma organização, com a finalidade de alcançar os efeitos positivos sobre o meio ambiente, eliminar ou compensar problemas ambientais decorrentes da sua atuação, assim como evitar que outros ocorram no futuro (Barbieri, 2016). Isso sugere que a gestão ambiental abranja o gerenciamento de riscos ambientais, ou seja, contemple desde ações de controle da poluição até práticas proativas de inovação em tecnologias, controlando os processos ao invés do resultado final (Potriche, 2017).

Para conduzir as ações pertinentes à gestão ambiental foi criado o Sistema de Gestão Ambiental (SGA), o qual pode ser adotado em diferentes processos produtivos, com o objetivo de planejar, organizar, controlar e mitigar os impactos ambientais (Netto, Gois \& Lucion, 2017). Ademais, esse sistema possui o propósito de elevar o potencial competitivo da empresa, ao associar sua imagem a práticas ambientalmente adequadas (J. C. G. F. Silva, Calábria, Silva \& Medeiros, 2007).

Os sistemas de certificação de um SGA têm sido uma opção cada vez mais utilizada pelas organizações. O padrão SGA de certificação mais reconhecido em todo o mundo é a norma ISO 14001 (T. O. Lima, Silva, Dutra \& Souza, 2018), criado no início da década de 1990 pela Organização Internacional para Padronização - ISO (Barbieri, 2016).

Além do SGA há outras estratégias que podem contribuir para o desenvolvimento de uma conduta ambientalmente adequada dentro das organizações, tais como a Produção Mais Limpa (PML) (Fernandes, Qualharini, Fernandes \& Nóbrega, 2015). A PML é uma estratégia aplicada à gestão ambiental, indicada como ferramenta que possibilita à empresa um funcionamento social e ambientalmente responsável (J. G. Santos \& Silva, 2017). Surgiu como uma maneira prática de tornar a indústria ciente de sua deficiência no manejo das questões ambientais, durante o período entre guerras e nas primeiras décadas ao final da Segunda Guerra Mundial. No cerne dessa questão, o foco da PML deve ser a redução na geração de resíduos, com a mudança de tratamento da poluição (chamadas técnicas fim-de-tubo) para a sua prevenção (Hens et al., 2018). 
Convém registrar, ainda, que a PML consiste em um instrumento de gestão aplicável, tanto em organizações que possuem certificação e têm interesse em minimizar a geração de resíduos, quanto naquelas que não possuem a certificação e desejam melhorar o desempenho ambiental (Fernandes et al., 2015). Assim, as empresas com atividades que possuem potencial impacto ambiental, principalmente as agroindústrias, devem aderir a um sistema de gerenciamento que atenda às exigências, ainda que o foco da empresa não seja a certificação (Moreira, 2006).

\subsection{Industrialização do palmito pupunha (Bactris gasipaes)}

A Pupunheira é uma palmeira nativa da América Latina Tropical (Graefe, Dufour, Zonneveld, Rodriguez \& Gonzalez, 2013). O seu interesse como produtora de palmito (pupunha) surgiu após a redução de reservas naturais da juçara (Euterpe edulis Martius) e do açaí (Euterpe oleraceae Martius), por meio do extrativismo (Rodrigues et al., 2017).

Nessa perspectiva, o uso da pupunha tem se apresentado como uma importante alternativa para o cultivo sustentável, pois além de colaborar para a redução da exploração predatória da juçara e açaí, possui crescimento célere e formação de perfilhos (Penteado, Santos \& Neves, 2010; Rodrigues et al 2017).

Com efeito, essas características fizeram com que a pupunheira se tornasse desejada entre os produtores, uma vez que o perfilhamento dispensa novos plantios por um longo período de tempo e o seu rápido crescimento permite a realização de cortes frequentes. Outras características, como alta produtividade, rusticidade, boa palatabilidade, ausência de oxidação do palmito, são comumente citados como vantagens econômicas da espécie (Penteado et al, 2010). No Brasil, a pupunheira vem sendo cultivada em várias regiões, como Santa Catarina, Paraná, Vale do Ribeira (SP), Goiás e Bahia, entre outros (Empresa Brasileira de Pesquisa Agropecuária [EMBRAPA], 2019).

O palmito pupunha, rico em minerais, fibras e aminoácidos, pode ser consumido minimamente processado ou na forma de conservas (Galdino \& Clemente, 2008). Em se tratando do palmito, é importante salientar que o Brasil, além de ser considerado o maior produtor e consumidor mundial do produto, também, é o maior exportador, responsável por cerca de $95 \%$ de todo o palmito consumido no mundo (EMBRAPA, 2019).

O processamento desses produtos possui etapas como: recepção, armazenamento refrigerado (opcional), limpeza final, corte e classificação (Resende, Saggin, Silva \& Flori, 2009). Na sequência, no processamento in natura realiza-se a remoção de cerosidade, corte, sanitização, enxague, pesagem e acondicionamento. Para o produto minimamente processado, inclui-se o corte em diferentes formatos e o acondicionamento refrigerado. Já para preparo de conservas, os cortes são encaminhados à imersão em salmoura de espera (sanitização), envase, pesagem, adição de salmoura ácida, exaustão e 
fechamento, esterilização comercial e resfriamento. Além disso, para este produto é realizado o teste de vedação, quarentena, rotulagem, armazenamento e transporte (Resende et al., 2009).

O palmito comercializado localiza-se na parte superior das palmeiras, as quais são constituídas por três camadas (bainhas): externa, mediana e interna. A primeira camada é aquela que envolve o palmito e possui cor esverdeada ou marrom. A segunda possui a coloração mais clara e uma quantidade inferior de fibras em relação à primeira. Ambas não são utilizadas na industrialização do palmito. A terceira camada, com o menor teor de fibras, corresponde à porção que produz o produto em conserva ou minimamente processado, e se divide em basal e central, de acordo com a sua textura (Oliveira, 2015).

Diante disso, pode-se verificar que as bainhas externas (também conhecidas como cascas) e medianas consistem em resíduos gerados durante o processamento do palmito.

Além das bainhas, há outras porções que chegam às unidades industriais e não são utilizadas no processamento, devido à textura inadequada, como a aérea - localizada logo acima das bainhas - e a caulinar, abaixo da basal. É importante destacar que a primeira, embora denominada aérea, não consiste nas folhagens. Além do mais, o seu estudo não é visto na literatura com a mesma frequência que as demais porções da haste. Todas essas porções supracitadas podem ser visualizadas na Figura 1.

Figura 1 - Pupunheira (B. gasipaes) e identificação das diferentes porções

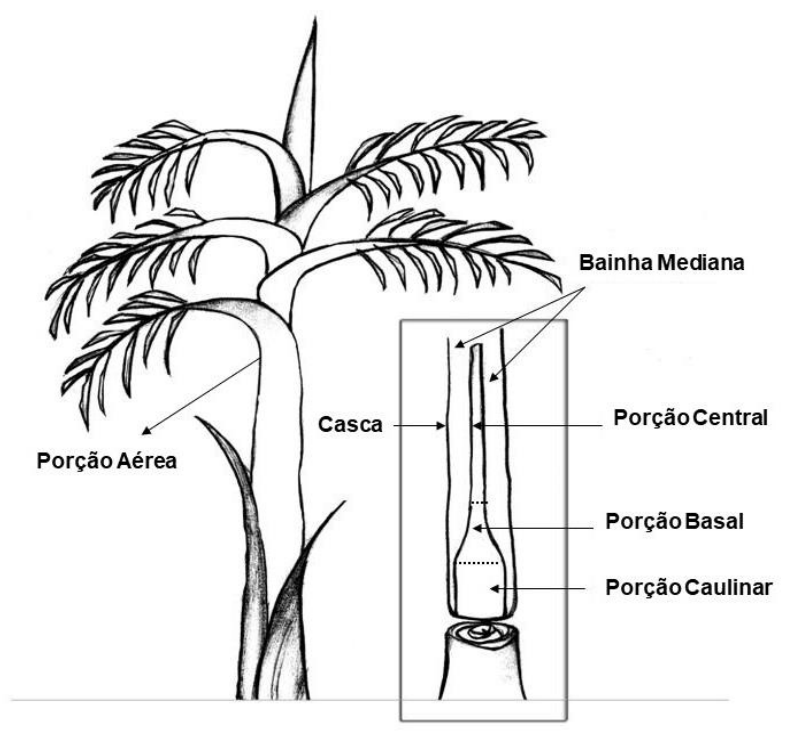

Fonte: Adaptado de Bolanho (2014).

O rendimento dos subprodutos, compostos por cascas, bainhas medianas e porção caulinar, corresponde a cerca de 80\% da matéria prima que chega às indústrias (Bolanho, Danesi \& Beléia, 2013). Neves et al. (2007) ainda destacam que o seu processo de degradação é lento, podendo produzir um passivo ambiental. 
Estima-se que, no Sul da Bahia, a produção de palmito renda cerca de 40 t.dia-1 de subproduto (Cabral et al., 2013). Já em Sinop (MT), um estudo constatou que os resíduos orgânicos gerados durante o processamento do palmito exalam mau cheiro, motivo pelo qual a sua destinação final deve ser célere. Além disso, outro estudo revelou que $40.000 \mathrm{~kg}$ destes resíduos são descartados mensalmente em vazadouro público (Paixão, Bagnara, Silva \& Silva, 2016).

Diante disso, o uso desses resíduos como matéria prima para criação de novos produtos surge como alternativa para mitigar os potenciais impactos ambientais e ao mesmo tempo Ihe agregar maior valor (Oliveira, 2015).

\section{Metodologia}

Com o propósito de se obter os nomes das indústrias processadoras de palmito pupunha no Estado do Paraná, realizou-se uma pesquisa por meio da internet. Em seguida, houve o contato com gestores/responsáveis, técnicos ou proprietários das agroindústrias quantificadas, por meio do envio de um convite. As empresas não tiveram seu nome divulgado, a fim de garantir o sigilo e confidencialidade dos dados e informações disponibilizadas. A pesquisa foi dividida em duas etapas, sendo a primeira o levantamento e análise dos dados referentes à gestão ambiental, e a segunda a coleta e análise físico-química dos resíduos sólidos.

\subsection{Levantamento de dados}

Esta etapa foi realizada por meio de um questionário, baseado no modelo utilizado por Menezes (2006). Tal documento teve o intuito de levantar as principais informações sobre o modo de gestão ambiental das indústrias, com a obtenção de dados que caracterizassem o processo produtivo, recursos utilizados na produção, fontes de energia e água, subprodutos gerados, sistema de tratamento dos resíduos e sua disposição final, bem como aspectos relacionados à ausência/presença de ações de Produção Mais Limpa.

Ainda, importa frisar que as informações solicitadas no questionário foram coletadas por recebimento do documento via correio eletrônico, no período de janeiro de 2018 a julho de 2019. As informações coletadas foram tabuladas na estrutura de um banco de dados, em planilha eletrônica, na ferramenta computacional Microsoft Excel. Para melhor compreensão dos resultados obtidos no questionário, foram calculadas relações entre a quantidade de água, efluentes e resíduos gerados por kg de produto processado, uma vez que os valores fornecidos pelas indústrias diziam respeito ao consumo, geração e produção mensais. 
$\mathrm{Na}$ análise qualitativa, utilizou-se a metodologia proposta por Moraes (2003), que visa à categorização dos dados e uma análise criteriosa das informações obtidas, possibilitando uma melhor compreensão dos fenômenos investigados.

\subsection{Coleta e caracterização físico-química dos resíduos sólidos}

A segunda etapa teve a finalidade de coletar e caracterizar os resíduos sólidos gerados nas unidades investigadas. Foram coletados subprodutos do palmito pupunha, previamente segregados em 3 partes: aéreo, bainha e caulinar.

Na sequência, após coletados, os resíduos foram submetidos a secagem em estufa à temperatura de $90^{\circ} \mathrm{C}$, durante $24 \mathrm{~h}$ e, posteriormente, trituradas em moinho de facas. Os principais componentes analisados foram: umidade (secagem em estufa), cinzas (incineração em mufla), proteínas (Kjeldahl), de acordo com as recomendações do Instituto Adolfo Lutz (2008) e fibras (detergente neutro), conforme a metodologia de D. J. Silva e Queiroz (2009).

Os resultados das análises realizadas em triplicata foram expressos em médias \pm desvio padrão e submetidos à análise de variância (ANOVA) e ao teste de Tukey com intervalo de 95\% de significância, utilizando o software Statistica 7.0.

\section{Resultados e discussões}

\subsection{Caracterização das agroindústrias processadoras de palmito pupunha}

O levantamento do número de indústrias produtoras de palmito pupunha revelou 7 unidades no estado, distribuídas pelos municípios de Umuarama, Cruzeiro do Oeste, Antonina, Guaraqueçaba, Curitiba e Morretes. Destas, 4 (57,14\%) enviaram o questionário respondido.

As indústrias participantes estão localizadas na mesorregião litorânea e noroeste do Paraná e possuem de 3 a 15 anos de atuação no mercado. Em relação ao porte, são classificadas, segundo a metodologia proposta pelo Serviço Brasileiro de Apoio às Micro e Pequenas Empresas [SEBRAE] (2013), como microempresa (3) e de pequeno porte (1). A Tabela 1 apresenta os dados coletados no que concerne à produção, realizada, na maior parte, de forma manual. 
Santos, L. N. dos., Bolanho, B. C., \& Danesi, E. D. G. (2021, jan./mar.). Gestão ambiental e caracterização de resíduos sólidos de agroindústrias de palmito pupunha do estado do Paraná

Tabela 1 - Distribuição das características referentes ao processamento de palmito pupunha nas quatro indústrias participantes do estudo

$\begin{array}{ccc}\text { Quantidade de } & \text { Quantidade de produtos } & \text { Produtos fabricados } \\ \text { palmito utilizado } & \text { fabricados } \\ \left(\mathrm{kg} \mathrm{mês-}^{1}\right) & \left(\mathrm{kg} \mathrm{mês}^{1}{ }^{1}\right)\end{array}$

$2.500 \quad 400 \quad \begin{gathered}\text { Minimamente processados: } \\ \text { espaguetes e toletes, rodelas, } \\ \text { picados. }\end{gathered}$

\begin{tabular}{|c|c|c|c|}
\hline PALM 2 & 84.360 & 15.960 & $\begin{array}{l}\text { Conservas e minimamente } \\
\text { processados: Tolete, rodela, } \\
\text { picado, spaghetti e lasanha de } \\
\text { pupunha }\end{array}$ \\
\hline PALM 3 & 12.000 & 6.000 & $\begin{array}{l}\text { Conservas e minimamente } \\
\text { processados: tolete, pedaço, } \\
\text { rodela, picado, fios e fatias. }\end{array}$ \\
\hline PALM 4 & 472.500 & 66.150 & $\begin{array}{c}\text { Conservas e minimamente } \\
\text { processados: inteiro, picado, } \\
\text { rodela, broto, aperitivo, spaghetti } \\
\text { e lasanha de pupunha. }\end{array}$ \\
\hline
\end{tabular}

Fonte: Elaborado pelos autores.

De acordo com a Tabela 1, verificou-se que a quantidade de palmito utilizada pelas indústrias varia, o que está relacionado ao porte das indústrias investigadas. Os produtos fabricados são apresentados de diversos formatos (picados, rodelas e toletes, lasanha, espaguete) e podem ser encontrados na forma de minimamente processados e em conservas.

Em relação à fonte de energia utilizada pelas empresas, todas atestaram utilizar energia elétrica. Além disso, todas também relataram adquirir ou regular os equipamentos da empresa com a finalidade de reduzir o consumo de energia. Ainda no que concerne à produção, a Tabela 2 dispõe das informações referentes à presença de caldeiras utilizadas pelas indústrias participantes. 
Tabela 2 - Distribuição das características referentes às caldeiras utilizadas pelas quatro indústrias participantes do estudo

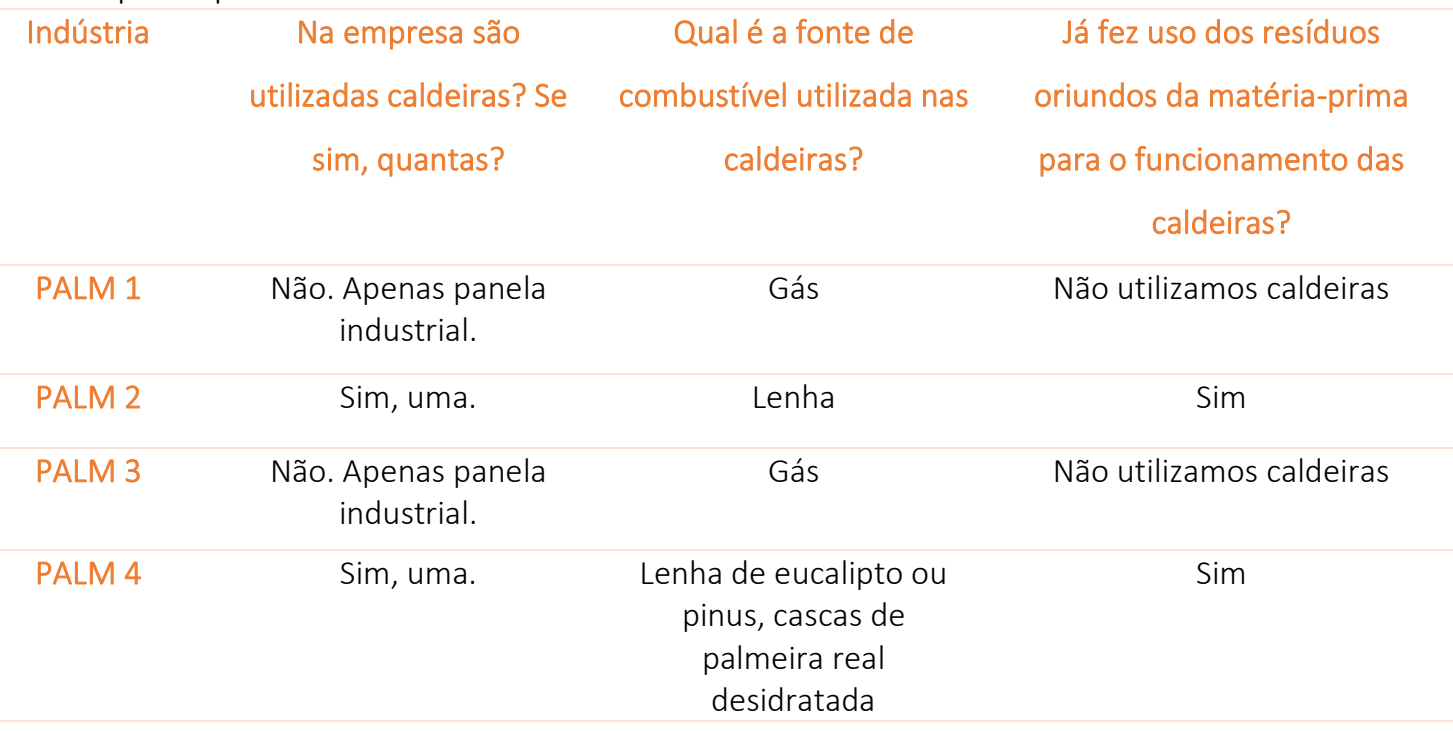

Fonte: Elaborado pelos autores.

O uso de caldeiras foi relatado por duas indústrias. Segundo Yamaguchi e Gomes (2016), esses dispositivos são utilizados pelas unidades processadoras de palmito com o objetivo de produzir vapor para a alimentação de máquinas térmicas, autoclaves (empregadas na esterilização de diversos materiais usados pela indústria) e o tratamento térmico do alimento.

Quanto à fonte de combustível para o seu funcionamento, destaca-se a resposta da PALM 4, a qual afirmou construir estufas para a desidratação de cascas e o seu posterior emprego como combustível. De acordo com a referida empresa, essas estufas consistem em estruturas metálicas revestidas por plásticos transparentes e piso em cimento alisado, construídas em área com grande exposição ao sol e próxima à caldeira. As cascas são dispostas em uma fina camada sobre paletes de madeira, para que ocorra a perda natural da umidade. A empresa ainda ressaltou que as cascas de palmeira real responderam melhor ao processo de desidratação em relação às cascas de pupunha, as quais apodreciam, impossibilitando a queima na caldeira. Atualmente, as estufas estão em desuso, pois a palmeira real é processada eventualmente. A PALM 2 também relatou já ter utilizado o resíduo da pupunha para alimentar as caldeiras. No entanto, para a indústria essa utilização se apresentou inviável, em decorrência do baixo poder calorífico do material. Almada, Souza, Santana e Gonçalves (2017) salientam que a umidade é um dos fatores que influenciam o aproveitamento energético de uma biomassa. Segundo os autores, o poder calorífico de um combustível varia inversamente com a presença de umidade no mesmo. O bagaço de cana-de-açúcar - resíduo viável para queima nas caldeiras apresenta umidade de cerca de 50\% (M. B. Silva \& Morais, 2008), enquanto que para os resíduos da pupunha este valor é superior a 80\% (Bolanho et al., 2013). 
Ainda sobre as caldeiras, cabe ressaltar que são fontes de emissão de poluentes. Diante disso, as indústrias que utilizam esse dispositivo foram questionadas sobre a presença de algum equipamento que visasse reduzir ou evitar a saída desses gases. Elas declararam utilizar equipamento do tipo multiciclone, que consiste em um processo de filtração, obtendo-se a separação de grande volume de partículas. Por outro lado, estudos realizados por Souza et al. (2009) e Yamaguchi e Gomes (2016), em indústrias processadoras de palmito, revelaram a emissão de grandes quantidades de poluentes atmosféricos sem qualquer tratamento.

Em relação à segurança nas caldeiras, uma das unidades admitiu realizar, anualmente, a inspeção de segurança do dispositivo por profissional habilitado (conforme previsto na NR-15 do Ministério do Trabalho e Emprego) e o treinamento de segurança em sua operação (conforme previsto pela NR-13) para seus profissionais.

A Tabela 3 apresenta as respostas das empresas relacionadas ao consumo de água durante o processo produtivo.

Tabela 3 - Distribuição das características referentes ao consumo de água das quatro indústrias participantes do estudo

\begin{tabular}{cccc} 
Indústria & Fonte de água & $\begin{array}{c}\text { Quantidade de água utilizada } \\
\text { mensalmente } \\
(\mathrm{L})\end{array}$ & $\begin{array}{c}\text { Razão entre água utilizada e } \\
\text { palmito processado } \\
\text { (L/kg de produto) }\end{array}$ \\
\hline PALM 1 & Poço & 5.000 & 12,5 \\
\hline PALM 2 & Poço & 228.000 & 14,29 \\
\hline PALM 3 & Rede pública & 60.000 & 10,00 \\
\hline PALM 4 & Poço & 343.089 & 5,19
\end{tabular}

Fonte: Elaborado pelos autores.

Notou-se que a principal fonte de água utilizada no processo produtivo é o poço artesiano. Apenas duas unidades afirmaram possuir um medidor de vazão de água. Além disso, as empresas expressaram o uso de distintas quantidades de água durante o processamento do palmito, sendo a PALM 4 a maior consumidora do recurso, com o uso mensal de $343.089 \mathrm{~L}^{\text {mês }}{ }^{-1}$. Evidencia-se que, embora a PALM 4 seja a maior consumidora de água dentre as indústrias participantes desta pesquisa, obteve o menor consumo ao relacioná-lo com a quantidade de produto processado $(5,19 \mathrm{~L} / \mathrm{kg}$ de palmito). Este fato está relacionado às boas práticas desenvolvidas pela indústria, que propiciaram a redução no consumo, quando comparado com as demais.

\subsection{Resíduos Líquidos}

Os principais efluentes das indústrias processadoras de palmito são provenientes do não aproveitamento da salmoura, da água de esterilização dos recipientes, lavagem dos equipamentos e a 
água de tratamento térmico do palmito em banho maria. As informações coletadas referentes à geração e ao tratamento desses líquidos foram dispostas na Tabela 4.

Tabela 4 - Distribuição das características referentes aos efluentes gerados nas quatro indústrias participantes do estudo

\begin{tabular}{|c|c|c|c|c|}
\hline Indústria & $\begin{array}{l}\text { Quantidade de } \\
\text { efluente gerado } \\
\text { mensalmente } \\
\text { (L) }\end{array}$ & $\begin{array}{l}\text { Razão entre } \\
\text { efluente gerado } \\
\text { e de produto } \\
\text { processado } \\
\text { (L/kg de } \\
\text { produto) }\end{array}$ & Tratamento aplicado & $\begin{array}{l}\text { Local de } \\
\text { despejo dos } \\
\text { efluentes após } \\
\text { tratamento }\end{array}$ \\
\hline PALM 1 & 1.100 & 2,75 & Fossa séptica & Fossa séptica \\
\hline PALM 2 & 13.680 & 0,86 & $\begin{array}{l}\text { Tratamento físico (gradeamento); } \\
\text { Biológico (reator anaeróbio de } \\
\text { fluxo ascendente - UASB - filtro } \\
\text { anaeróbio) e desinfeç̧ão (cloro). }\end{array}$ & Corpo hídrico \\
\hline PALM 3 & 50.000 & 8,33 & $\begin{array}{c}\text { Rede de tratamento com } \\
\text { peneiras, decantação e adição de } \\
\text { cloro }\end{array}$ & Corpo hídrico \\
\hline PALM 4 & 268.000 & 4,05 & $\begin{array}{c}\text { Estação de tratamento de } \\
\text { efluente composta por fossa } \\
\text { séptica, filtros anaeróbios, caixa } \\
\text { de decantação, caixa de cloração } \\
\text { e contato, calha Parshall }\end{array}$ & Corpo hídrico \\
\hline
\end{tabular}

Fonte: Elaborado pelos autores.

De acordo com a Tabela 4, observou-se uma ampla variação na geração de efluentes entre as unidades. Evidencia-se que a PALM 3, embora não seja a maior processadora de palmito, é a que gera maior quantidade de efluente, ao considerar a quantidade de produto processado. Essa geração pode estar relacionada às práticas adotadas pela empresa durante o processo produtivo, as quais acarretam elevados desperdícios de água e, consequentemente, geração de efluente. Já a PALM 1, por possuir um processo mais simples, o seu único efluente descartado (a salmoura de palmito) tem como destino a fossa e as demais águas residuais são utilizadas na irrigação das pupunheiras, as quais ficam na mesma propriedade em que a fábrica está instalada. As demais indústrias possuem uma Estação de Tratamento de Esgoto (ETE) e destinam o efluente, após o tratamento, a um corpo hídrico receptor.

Um estudo realizado no estado do Mato Grosso reportou que os efluentes produzidos por uma indústria de conservas são destinados, sem tratamento, a uma vala localizada em frente à fábrica, passando apenas por peneira para retenção de restos de alimentos e outros resíduos (Paixão et al., 2016). No Pará, as águas residuais de uma instalação de palmito são escoadas até uma lagoa artificial e recebem apenas a adição de cloro antes de serem encaminhados para o curso d'água (Souza et al., 2009). 
No Brasil, o despejo de efluente diretamente nos corpos hídricos deve obedecer a parâmetros estabelecidos por normas, como a Resolução 430, de 2011, do Conselho Nacional do Meio Ambiente CONAMA. Segundo Paixão et al. (2016), o correto tratamento das águas residuais é fundamental, uma vez que, além de proporcionar a remoção de contaminantes, deve corrigir a presença de elevadas cargas orgânicas, acidez, turbidez e até mesmo temperatura.

É importante salientar que a água utilizada no processo de autoclavagem é passível de reutilização, uma vez que não possui alto teor de carga orgânica. Logo, sugere-se sua reutilização no processo de pré-lavagem da matéria prima ou na irrigação de pastagens e/ou plantação de palmito que se encontram próximas às fábricas.

\subsection{Resíduos Sólidos}

\subsubsection{Quantificação e descarte dos resíduos sólidos gerados no beneficiamento do palmito pupunha}

No que diz respeito à geração de resíduos, os principais setores das unidades, que se destacam na sua produção, são os de descasque e de processamento. Para Seben, Paula e Viana (2012), o grande volume de biomassa originário do descascamento faz com que essa etapa ofereça a maior possibilidade de valorização dos resíduos.

Vale lembrar que esses materiais podem ser denominados de acordo com as camadas a que pertencem, sendo: bainhas, parte caulinar e aérea. É importante reafirmar que esta, embora denominada aérea, não consiste nas folhagens e está localizada logo acima das bainhas. As indústrias foram questionadas quanto à separação das três camadas supracitadas e apenas a PALM 2 declarou realizar a separação. Deve-se ressaltar que as folhas não foram caracterizadas e quantificadas neste estudo, em decorrência de permanecerem, em grande parte, no local da colheita.

Schmitz, Heck, Hermann, Vegini e Tavares (2018) classificam essa biomassa de acordo com a norma NBR 10.004, da ABNT, em Classe IIA - Inertes, ou seja, os resíduos que têm como propriedades a solubilidade em água, a biodegradabilidade e a combustibilidade. Estes autores ainda ressaltam que sua geração é uma fonte de degradação do meio ambiente, caso não seja adequadamente descartado.

A Tabela 5 dispõe as informações da geração e destinação dos subprodutos nas quatro instalações. 
Tabela 5 - Distribuição das características referentes à geração dos subprodutos da industrialização do palmito nas quatro indústrias participantes do estudo

\begin{tabular}{|c|c|c|c|c|c|}
\hline Indústria & $\begin{array}{l}\text { Peso da } \\
\text { haste }(\mathrm{kg})\end{array}$ & $\begin{array}{l}\text { Peso de palmito } \\
\text { comercializado por } \\
\text { haste }(\mathrm{kg})\end{array}$ & $\begin{array}{c}\text { Peso de resíduo } \\
\text { gerado por kg de } \\
\text { palmito } \\
\text { processado }(\mathrm{kg})\end{array}$ & $\begin{array}{l}\text { Produção } \\
\text { diária } \\
\text { (kg/dia) }\end{array}$ & $\begin{array}{l}\text { Para onde elas sã } \\
\text { destinadas? }\end{array}$ \\
\hline
\end{tabular}

$\begin{array}{llrr}\text { PALM } 1 & 5,8 & 5,25 & 110,00 \quad \begin{array}{r}\text { Meio ambiente. Ainda não } \\ \text { tem lucro com o resíduo }\end{array}\end{array}$

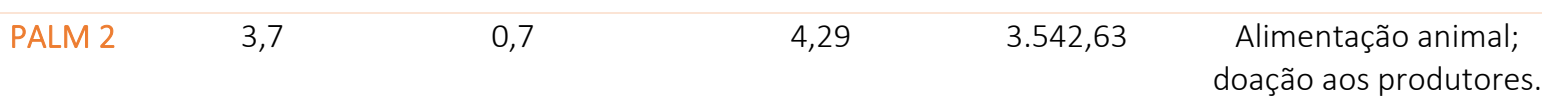

$\begin{array}{lllllll}\text { PALM } 3 & - & - & - & - & 285,71 & \text { São destinadas para a }\end{array}$ própria plantação de palmito, como adubo

$\begin{array}{lllll}\text { PALM } 4 & 4,5 & 0,67 & 5,72 & 18.018,00\end{array}$

Fonte: Elaborado pelos autores.

Segundo a Tabela 5, a PALM 4 possui a maior geração de resíduos, sendo que a cada haste da pupunha que chega à indústria (já retiradas as folhas e outros resíduos que ficam no campo), 85\% é caracterizada como resíduo. Já a PALM 2 apresentou o menor percentual (81,08\%) ao mostrar o aproveitamento de matéria prima por haste.

Na literatura, os valores apresentados por Schmitz et al. (2018) e Seben et al. (2012) são, respectivamente, $77,5 \%$ e $95 \%$.

Analisando os dados para fins de cálculo da quantidade de subprodutos gerados nas quatro indústrias de processamento de palmito, constatou-se a produção de 21.956,34 $\mathrm{kg} \mathrm{dia}^{-1}$ de resíduos (5,11 kg de resíduo por kg de palmito). Estudos realizados em agroindústrias de conservas de palmito no Brasil revelaram a geração de $2.000 \mathrm{~kg} \mathrm{dia}^{-1} \mathrm{em}$ unidades do Mato Grosso (Paixão et al., 2016) e do Pará (Souza et al., 2009), $40.000 \mathrm{~kg} \mathrm{dia}^{-1}$ no sul da Bahia (Cabral et al., 2013) e $340.000 \mathrm{~kg} \mathrm{dia}^{-1}$ em 50 instalações de Santa Catarina (Schmitz et al., 2018).

Em relação à destinação final nas unidades participantes deste estudo, observou-se que uma das empresas deixa seus resíduos expostos a céu aberto, nas proximidades da instalação, tornando-se um passivo ambiental. Já as demais afirmaram destiná-los a alimentação animal de terceiros, ou em adubo na própria propriedade, o que também foi identificado por Yamaguchi e Gomes (2016). Schmitz et al. (2018) apontaram o retorno do resíduo à lavoura como o mais citado entre as empresas participantes de seu estudo, o qual acontece de três formas: disposição do resíduo diretamente no solo 
da lavoura, compostagem e produção de húmus ou uso como componente de substrato para mudas da palmeira.

No que diz respeito aos custos/lucros com o destino dos resíduos, todas as unidades atestaram não obter lucro com o descarte e apenas uma delas revelou possuir custos trabalhistas com os funcionários que realizam a destinação, assim como com o combustível utilizado no transporte, e a manutenção do caminhão.

A PALM 2, por sua vez, informou a compra de uma máquina para triturar os resíduos, agregando-Ihes maior valor econômico. No entanto, o processo ainda está em fase de testes e os custos repassados aos agricultores, que adquirem o material, ainda se referem apenas aos gastos de energia durante o processo de trituração. Uma alternativa para as empresas seria realizar, após a trituração, a secagem dos resíduos, de forma natural ou por estufas, o que facilitaria o armazenamento e o transporte dos resíduos. Portanto, o reaproveitamento dos resíduos da pupunha, além de contribuir para a redução de potenciais impactos ambientais, resultantes de seu descarte e do desperdício de importantes componentes da matéria prima, poderá ser uma fonte de renda para a cadeia produtiva.

\subsubsection{Caracterização química dos resíduos sólidos gerados no beneficiamento do palmito pupunha}

Os subprodutos do palmito pupunha consistem em uma excelente alternativa para o emprego de usos mais nobres que a alimentação animal ou adubo. Isso porque há três importantes fatores que justificam sua exploração: geração, disponibilidade e composição. Diante disso, foi realizada a caracterização dos principais componentes do resíduo, os quais apresentam elevado teor de umidade, sendo a parte aérea a que apresenta o maior valor $\left(89,93 \pm 2,50 \mathrm{~g} .100 \mathrm{~g}^{-1}\right)$, seguida da caulinar $(89,27 \pm$ 0,97 g.100g-1) e bainha ( $82,50 \pm 1,40$ g.100g-1 $)$. Bolanho et al. (2013), ao caracterizar as bainhas e a porção caulinar, encontraram valores semelhantes aos deste estudo.

A Tabela 6 apresenta os demais componentes do resíduo após serem submetidos ao processo de desidratação.

Tabela 6 - Composição química dos subprodutos desidratados do palmito pupunha provenientes de uma das indústrias participantes deste estudo

\begin{tabular}{cccc} 
Parte do subproduto & $\begin{array}{c}\text { Cinzas } \\
\left(\mathrm{g} \cdot 100 \mathrm{~g}^{-1} \text { b.s. }\right)\end{array}$ & $\begin{array}{c}\text { Proteínas } \\
\left(\mathrm{g} \cdot 100 \mathrm{~g}{ }^{-}{ }^{\mathrm{b}} \text { b.s. }\right)\end{array}$ & $\begin{array}{c}\text { Fibras } \\
\left(\mathrm{g} \cdot 100 \mathrm{~g}-{ }^{1} \text { b.s. }\right.\end{array}$ \\
\hline Aéreo & $4,93^{\mathrm{b}} \pm 0,03$ & $11,36^{\mathrm{a}} \pm 0,02$ & $61,12^{\mathrm{a}} \pm 1,98$ \\
Bainha & $3,50^{\mathrm{c}} \pm 0,08$ & $4,37^{\mathrm{c}} \pm 0,29$ & $54,69^{\mathrm{b}} \pm 0,26$ \\
Caulinar & $5,89^{\mathrm{a}} \pm 0,06$ & $6,22^{\mathrm{b}} \pm 0,17$ & $45,53^{\mathrm{c}} \pm 0,58$
\end{tabular}

Fonte: Elaborado pelos autores.

b.s. = base seca. Médias seguidas pela mesma letra (em cada coluna) não diferiram estatisticamente $(p<0,05)$ pelo teste de Tukey. 
Ao considerar o material em base seca, verificou-se que as fibras são os principais componentes do resíduo. Pode-se observar que a parte aérea é a mais fibrosa $\left(61,12 \mathrm{~g} \cdot 100 \mathrm{~g}^{-1}\right)$, em comparação com as demais $\left(45,53\right.$ e $\left.54,69 \mathrm{~g} \cdot 100 \mathrm{~g}^{-1}\right)(\mathrm{p}<0,05)$.

Para Bolanho, Danesi e Beléia (2015), o conteúdo de fibras alimentares presentes nas farinhas obtidas a partir de subprodutos da pupunha variou de 62 a 71 g.100g-1, valores maiores que os encontrados nesse estudo. Elleuch et al. (2011) afirmaram que o consumo de alimentos com altos teores de fibras alimentares é muito importante para a saúde, já que possui efeito na prevenção de várias doenças, como diabetes, obesidade, distúrbios gastrointestinais e até câncer de cólon. Assim, a destinação dos subprodutos do palmito pupunha para obtenção de fibras alimentares é uma vertente que pode ser explorada.

A porção aérea apresentou o maior teor de proteínas $(11,36$ g.100g-1) e a caulinar o maior de cinzas $\left(5,89 \mathrm{~g} \cdot 100 \mathrm{~g}^{-1}\right)$. Cabe ressaltar que ainda há outros componentes presentes no resíduo em menores quantidades, como lipídios, vitaminas, açúcares e compostos antioxidantes (Bolanho et al., 2013)

Devido à composição química desses resíduos, há diversas pesquisas que avaliam sua aplicação em distintos setores, a saber: enriquecimento de alimentos (Barbosa et al., 2011; Egea et al., 2018; Fiorda, Soares, Los et al., 2018), produção de biofertilizante (F. A. M. Silva, Prado \& Silva, 2009), geração de biogás (Vidal, 2014) e materiais biossorventes (Crespão, 2017; Honorato et al., 2015).

\subsubsection{Gerenciamento dos resíduos sólidos gerados nas indústrias de beneficiamento do palmito pupunha}

Além dos subprodutos acima descritos, nas indústrias investigadas há geração de outros resíduos, em menor índice, como papelão, plásticos, vidros, alumínios e lixo de escritório. Paixão et al. (2016), ao quantificarem esses materiais em uma indústria de conservas de médio porte, identificaram a geração, ao final do processo, de $6.000 \mathrm{~kg}$.

Os resíduos gerados nos laboratórios de análises também não foram quantificados neste estudo. Tais materiais consistem em restos de palmito, resultantes das análises necessárias para a execução das curvas de acidificação e para a liberação dos lotes. Segundo uma das instalações, esses resíduos são descartados como orgânicos e além deles há o descarte de frascos vazios (utilizados nas análises de pH), destinado aos recicláveis. Há também parcelas líquidas, que consistem em salmoura ácida, solução tampão e solução de Cloreto de Potássio $(\mathrm{KCl})$ as quais são descartadas na pia e encaminhadas à estação de tratamento de efluentes. 
Todas as indústrias afirmaram possuir um plano de gerenciamento de resíduos (que contemple todos os resíduos gerados), porém apenas duas delas afirmaram não implementar ações para bloquear/eliminar a produção de resíduo no ponto onde o mesmo é produzido.

\subsection{Gestão Ambiental e Produção Mais Limpa (PML)}

As agroindústrias foram interrogadas quanto à presença de Sistema de Gestão Ambiental (SGA) e apenas a PALM 2 atestou possuir, embora não tenha a certificação. Quanto às opções de PML, apenas a PALM 4 afirmou conhecê-las. Ao serem questionados sobre o interesse em adotar a PML ou um sistema de gestão integrado de resíduos, as respostas foram as seguintes:

- "Gostaria de colocar em prática, ainda falta muito" (PALM 1);

- "Temos interesse em conhecer" (PALM 2);

- "Não sei, preciso conhecer" (PALM 3);

- "Sim" (PALM 4).

As organizações que participaram desta pesquisa não adotam nenhuma das normas ISO, nem possuem uma equipe que realize a conscientização e treinamento dos funcionários em relação às questões ambientais. Apesar disso, duas indústrias disseram que há supervisão aos funcionários em relação às práticas ambientais. Com efeito, a conscientização dos funcionários é primordial para que ocorra a efetiva adoção de ações que se propõem a prevenir e reduzir a geração de resíduos.

Ao serem questionados sobre os maiores problemas da empresa no que tange ao meio ambiente, verificou-se o destino dos resíduos sólidos como o mais relatado. A Tabela 7 dispõe os problemas e as dificuldades das empresas no que concerne à gestão ambiental.

Uma das empresas ainda relatou que a região em que está instalada não oferece prestadores de serviços qualificados, licenciados ou cadastrados para a prestação de serviços necessários à gestão ambiental (monitoramento de efluentes, de emissões das caldeiras, coleta e transporte de resíduos sólidos e limpeza das unidades da ETE), o que acarreta custos elevados para o atendimento das determinações legais e condicionantes ambientais, visto que necessita contratar prestadores de serviços de outras cidades. 
Tabela 7 - Relato das dificuldades na gestão ambiental vivenciadas pelas quatro indústrias participantes do estudo
Indústria
Relato
PALM 1 - Aproveitar melhor os resíduos. Já o utilizei para a produção de farinha, porém preciso de uma estufa maior para a secagem dos resíduos.
PALM 2 - A parceria com produtores tem funcionado bem para a retirada das cascas, porém tem que sempre estar atento com as ausências na retirada, pois isso gera transtornos.
PALM 3 - Destino dos resíduos sólidos e conseguir renovação da licença de operação do IAP, que foi solicitada em junho de 2016 e ainda (2018) não foi liberada.
PALM 4 - Ausência de coleta pública de resíduos na região;
- Ausência de empresas licenciadas para coleta e transporte de resíduos na região;
- Poucas alternativas de coletores de resíduos recicláveis na região;
- Custos associados à destinação das cascas de palmito;
- Dificuldade na conscientização ambiental de funcionários;
- Dificuldades para encontrar alternativas para a redução no consumo de água;
- Absorver a gestão ambiental nas rotinas da empresa, deixando de entendê-la como processo burocrático.

Fonte: Elaborado pelos autores.

Por fim, outra unidade revelou que a dificuldade para descartar os resíduos não é um problema vivenciado apenas por ela, mas por todos os produtores que participam da Feira do Agricultor do município em que está instalada, os quais têm dificuldades para encontrar uma destinação ambientalmente adequada para os resíduos orgânicos por eles gerados, realidade também relatada por Santoro, Jorge, Oliveira, Silva, \& Rodrigues (2018).

Para Schmitz et al. (2018) as empresas destinam os resíduos gerados da maneira que thes é mais oportuna e prática, já que não há um processo que transforme a condição desses resíduos em um novo produto.

Embora as indústrias participantes afirmem não conhecer as ações de PML, pode-se identificar algumas dessas ações, de acordo com os 3 níveis propostos pela PML, como a reutilização dos resíduos do palmito na caldeira (nível 2) e o destino dos subprodutos à alimentação animal e ao uso de adubos (nível 3).

\section{Considerações finais}

O trabalho demonstrou que as indústrias participantes deste estudo geram elevadas quantidades de resíduos sólidos oriundos da matéria prima, caracterizados como bainhas, porções 
caulinar e aérea, os quais apresentam alto teor de umidade $(82,50$ a $89,93 \%)$, seguido por fibras, proteínas e cinzas.

É importante evidenciar que práticas de reutilização, como o emprego dos resíduos sólidos nas caldeiras, foram adotadas por duas indústrias, no entanto, não lograram êxito. Novas tentativas vêm sendo testadas, como a de uma unidade que afirmou adquirir um triturador para os resíduos, visando agregar valor na venda do material. Essas ações demonstram o interesse das empresas em encontrar um destino mais nobre aos resíduos, o qual deve continuar a ser pesquisado. A alta geração destes subprodutos (aproximadamente $5,11 \mathrm{~kg}$ de resíduo por $\mathrm{kg}$ de palmito processado) atrelada à composição química e as poucas opções de reuso tornam o gerenciamento desses materiais como a principal dificuldade na gestão ambiental das indústrias. Além disso, a indústria de maior porte apresentou a menor taxa de consumo de água (5,19 L/kg de palmito processado), o que evidencia a possibilidade de redução no uso do recurso pelas demais participantes.

Logo, sugere-se parcerias entre as indústrias e o meio acadêmico com a finalidade de buscar soluções menos impactantes ao meio ambiente, por meio de práticas que visam à otimização no uso dos recursos naturais e, ao mesmo tempo, o emprego de novas aplicações aos resíduos e efluentes gerados.

\section{Referências}

Almada, T. S. A., Souza, M. J. R., Santana, A. F. P. \& Gonçalves, R. F. B. (2017). Caracterização da casca do palmito para uso energético. Enciclopédia Biosfera, 14 (26), 144-151.

Barbieri, J. C. (2016). Gestão Ambiental Empresarial. (4a ed.) São Paulo: Saraiva.

Barbosa, J. R., Beltrame, S. C., Bragatto, M. M., Débia, P. J. G., Bolanho, B. C. \& Danesi, E. D. G. (2011). Avaliação da composição e dos parâmetros tecnológicos de farinhas produzidas a partir de subprodutos agroindustriais. Revista Tecnológica, (Edição Especial V), pp. 21-28. https://doi.org/10.4025/revtecnol.v0i0.14954.

Bolanho, B. C. (2014). Caracterização de farinhas obtidas de subprodutos de palmito pupunha. Tese de doutorado, Universidade Estadual de Londrina, Londrina, PR, Brasil.

Bolanho, B. C.; Danesi, E. D. G. \& Beléia, A. Del P. (2013). Peach Palm (Bactris gasipaes Kunth) Characterization and the Potential of by-products Flour Processing. Food Science and Technology Research, 19 (6), 1061-1069.

Bolanho, B. C.; Danesi, E. D. G. \& Beléia, A. Del P. (2015). Carbohydrate composition of peach palm (Bactris gasipaes Kunth) by-products flours. Carbohydrate Polymers, 124, 196-200. https://doi.org/10.1016/j.carbpol.2015.02.021

Cabral, I. S., Azevêdo, J. A., Almeida, F. M., Pereira, L. G. R., Araújo, G. G. L., Cruz, C. L. S., Nogueira, A. S., Souza, L. L. \& Oliveira, G. A. (2013). Performance and characteristics of carcass and non-carcass components of lambs fed peach-palm by-product. Tropical Animal Health and Production, 45 (8), 1737-1743. https://doi.org/10.1007/s11250-013-0424-1 
Crespão, L. M. P. (2017). Biossorção do corante têxtil vermelho 4B utilizando resíduos agroindustriais após colonização fúngica. Dissertação de mestrado, Universidade Estadual do Oeste do Paraná, Toledo, PR, Brasil.

Egea, M. B., Bolanho, B. C., Lemes, A. C., Bragatto, M. M., Silva, M. R., Carvalho, J. C. M. \& Danesi, E. D. G. (2018). Low cost cassava, peach palm and soy by-products for the nutritional enrichment of cookies: Physical, chemical and sensorial characteristics. International Food Research Journal, 25 (3), 1204-1212.

Elleuch, M., Bedigian, D., Roiseux, O., Besbes, S., Blecker, C. \& Attia, H. (2011). Dietary fibre and fibrerich by-products of food processing: Characterization, technological functionality and commercial applications: A review. Food Chemistry, 124 (2), 411-421.

https://doi.org/10.1016/j.foodchem.2010.06.077

Empresa Brasileira de Pesquisa Agropecuária. (2019). Transferência de tecnologia florestal. Pupunha. Recuperado em 18 fevereiro, 2020, de https://www.embrapa.br/florestas/transferencia-detecnologia/pupunha/tema

Fermino, M. H., Gonçalves, R. S., Battistin, A., Silveira, J. R. P., Busnello, A. C. \& Trevisam, M. (2014). Palm fiber as substrate for vegetables. Horticultura Brasileira, 32, (4), 404-408. https://doi.org/10.1590/S0102-053620140000400006.

Fernandes, J. L., Gualharini, E. L., Fernandes, A. S. da C., Nóbrega, M. J. R. da. Um estudo da produção mais limpa na gestão ambiental. Revista Augustus, 20 (39), 52-64.

https://doi.org/10.15202/10.15202/19811896.2015v20n39p52.

Ferreira, B. S., Santos, D. F. L., Thomaz, A. G. B. \& Rebelato, M. G. (2018). Ecoinovação em uma Agroindústria Sucroenergética: A Implantação do Projeto de Águas Residuais Zero. Revista de Gestão Ambiental e Sustentabilidade - GeAS, 7 (1), 131-145. https://doi.org/10.5585/geas.v7i1.719

Fiorda, F. A., Soares, M. S. JR., Silva, F. A. \& Souto, L. R. F. (2013). Amaranth flour, cassava starch and cassava bagasse in the production of gluten-free pasta: Technological and sensory aspects. International Journal of Food Science and Technology, 48 (9), 1977-1984. https://doi.org/10.1111/ijfs.12179

Galdino, N. O. \& Clemente, E. (2008). Palmito de pupunha (BactrisgasipaesKunth.), composição mineral e cinética de enzimas oxidativas. Ciência e Tecnologia de Alimentos, 28 (3), 540-544. https://doi.org/10.1590/S0101-20612008000300006.

Graefe, S., Dufour, D., Zonneveld, M. V., Rodriguez, F. \& Gonzalez, A. (2013). Peach palm (Bactris gasipaes) in tropical Latin America: Implications for biodiversity conservation, natural resource management and human nutrition. Biodiversity and Conservation, 22 (2), 269-300. https://doi.org/10.1007/s10531-012-0402-3.

Hens, L., Block, C., Cabello-Eras, J. J, Sagastume-Gutierez, A., Garcia-Lorenzo, D., Chamorro, C., Mendoza, K. H., Haeseldonckx, D. \& Vandecasteele, C. (2018). On the evolution of "Cleaner Production" as a concept and a practice. Journal of Cleaner Production, 172 (20), 3323-3333. https://doi.org/10.1016/j.jclepro.2017.11.082

Honorato, A. C., Machado, J. M., Celante, G., Borges, W. G. P., Dragunski, D. C. \& Caetano, J. (2015). Biossorção de azul de metileno utilizando resíduos agroindustriais. Revista Brasileira de Engenharia 
Santos, L. N. dos., Bolanho, B. C., \& Danesi, E. D. G. (2021, jan./mar.). Gestão ambiental e caracterização de resíduos sólidos de agroindústrias de palmito pupunha do estado do Paraná

Agrícola e Ambiental, 19 (7), 705-710. https://doi.org/10.1590/1807-1929/agriambi.v19n7p705710.

Instituto Adolfo Lutz (2008). Métodos físico-químicos para análise de Alimentos (Edição IV, 1a ed. digital). São Paulo: Autor.

Lima, L. P., Ferreira, A. G., Vaz, L. R. L., Andrade, W. R. \& Ferreira, C. F. S. (2018). Método para Seleção de Sistemas de Tratamento de Efluentes em Agroindústrias de Micro e Pequeno Porte. Revista Engenharia na Agricultura, 26 (4), 334-342. https://doi.org/10.13083/reveng.v26i4.964

Lima, T. O., Silva, S. C. da, Dutra, J. M., Souza, A. P. de. (2018). A efetividade dos sistemas de gestão ambiental como fator competitivo: estudo de caso de empresas do polo industrial de Manaus. Amazon Business Research, (2), 154-174.

Los, P. R., Simões, D. R. S., Leone, R. S., Bolanho, B. C., Cardoso, T. \& Danesi, E. D. G. (2018). Viability of peach palm by-product, Spirulina platensis, and spinach for the enrichment of dehydrated soup. Pesquisa Agropecuária Brasileira, 53 (11), 1260-1268. https://doi.org/10.1590/s0100$204 \times 2018001100008$

Menezes, C. S. (2006). Resíduos gerados nas agroindústrias na microrregião de Propriá e as práticas de gestão ambiental adotadas. Dissertação de mestrado, São Cristóvão, SE, Brasil.

Moraes, R. Uma tempestade de luz: a compreensão da possibilidade pela análise textual discursiva. (2003). Revista Ciência \& Educação, 9 (2), 191-211. https://doi.org/10.1590/S151673132003000200004

Moreira, M. S. (2006). Estratégia e Implantação do Sistema de Gestão Ambiental Modelo ISO 14000. (3a ed.). Nova Lima: INDG Tecnologia e Serviços Ltda.

Netto, D.; Gois, G. R. \& Lucion, J. (2017). Fundamentos teóricos e conceituais da gestão ambiental. In: Dal Forno, M. A. R. (org.). Fundamentos da Gestão Ambiental. (Cap. 2, p. 23-46). Porto Alegre: UFRGS.

Neves, E. J. M., Santos, A. F., Rodigheri, H. R., Corrêa, C. JR., Bellettini, S. \& Tessmann, D. J. (2007). Cultivo da Pupunheira para Palmito nas Regiões Sudeste e Sul do Brasil. (Circular Técnica, 143). Colombo, PR: Embrapa. Recuperado em 15 julho, 2019, de https://ainfo.cnptia.embrapa.br/digital/bitstream/CNPF-2009-09/42550/1/Circular143.pdf

Oliveira, L. F. (2015). Resíduo do processamento de palmito de pupunha: Estudo físico, químico, tecnológico e toxicológico. Dissertação de Mestrado, Universidade Federal de Goiás, Goiânia, GO, Brasil.

Paixão, F. L. M., Bagnara, D. M., Silva, L. S. \& Silva, A. S. (2016). Gestão Ambiental: o caso de uma indústria de alimentos localizada no município de Sinop-MT. Anais do XIII Congresso Nacional de Meio Ambiente de Poços de Calda, Poços de Calda, MG, Brasil, 306.

Penteado, J. F. JR.; Santos, A. F. \& Neves E. J. M. (2010). Rentabilidade econômica do cultivo da pupunheira (Bactris gasipaes Kunth), destinada à produção de palmito no Litoral de Santa Catarina. (Embrapa Florestas, 195), Colombo, PR: Empresa Brasileira de Pesquisa Agropecuária, Embrapa Florestas, Ministério da Agricultura, Pecuária e Abastecimento. Recuperado em 18 agosto, 2019, de https://ainfo.cnptia.embrapa.br/digital/bitstream/item/24480/1/Doc195.pdf 
Piacente, F. (2005). Agroindústria Canavieira e o Sistema de Gestão Ambiental: O Caso das Usinas Localizadas nas Bacias Hidrográficas dos Rios Piracicaba, Capivari e Jundiaí. Dissertação de Mestrado, Universidade Estadual de Campinas, Campinas, SP, Brasil.

Potriche, L. (2017). Proposta de um modelo de avaliação de proatividade em gestão ambiental. Dissertação de mestrado, Universidade do Rio Grande do Sul, Porto Alegre, RS, Brasil.

Resende, J. M. Saggin, O. J. Jr., Silva, E. M. R. \& Flori, J. E. (2009). Palmito de Pupunha in Natura e em Conserva. Brasília: Embrapa.

Santoro, J. O. B. Jorge, E. C., Oliveira, C. M. S., Silva, M. S. \& Rodrigues, A. G. (2018). Implantação de medidas de organização da Feira de Produtores Orgânicos do Município de Pinheiral - RJ. Cadernos de Agroecologia, 13 (1).

Santos, J. G., Silva, Y. D. T. (2017) Práticas de gestão ambiental e produção mais limoa: uma análise do processo produtivo da cachaça Sanhaçu. Revista Produção e Desenvolvimento, 3 (3), 1-17.

Santos, S. P., Araújo, I. R. C., Morais, J. \& Vargas, R. S. (2018). Estudo de caso: reuso de madeira em agroindústria. Revista Eletrônica EcoDebate, (2.943). Recuperado em 15 agosto, 2019, de https://www.ecodebate.com.br/wp-content/uploads/2018/03/20180319-180319estudo-de-caso_reuso-de-madeira-em-agroindustria.pdf.

Santos, V. A. L. \& Pierre, F. C. (2018). Fatores chaves para implantar um sistema de gestão ambiental em uma agroindústria. Tekhne e Logos, 9 (1) 31-42.

Seben, L. L.; Paula, I. C. \&Viana, S. G. (2012). Análise do processo de beneficiamento da Palmeira Real da Austrália (palmito em conserva) para determinação das variáveis que influenciam as operações de valorização de seus resíduos. Produto \& Produção, 13 (1), 75-

92. https://doi.org/10.22456/1983-8026.24238

Serviço Brasileiro de Apoio às Micro e Pequenas Empresas. (2013). Anuário do Trabalho na Micro e Pequena Empresa (6a ed.). São Paulo: DIEESE. Recuperado em 10 julgo, 2019, de https://m.sebrae.com.br/Sebrae/Portal\%20Sebrae/Anexos/Anuario\%20do\%20Trabalho\%20Na\%20 Micro\%20e\%20Pequena\%20Empresa_2013.pdf

Schmitz, W., Heck, T. C., Hermann, K. L., Vegini, A. A. \& Tavares, L. B. B. (2018) Levantamento sobre a produção de resíduos sólidos gerados no processamento de palmito em Santa Catarina, Brasil. Revista Educação Ambiental em ação, 16 (63). Recuperado em 18 agosto, 2019, de http://www.revistaea.org/artigo.php?idartigo=3091

Silva, D. J. \& Queiroz, A. C. (2009). Análise de alimentos: métodos químicos e biológicos. Viçosa: UFG.

Silva, F. A. M.; Prado, J. E. \& Silva, R. B. (2009). Aproveitamento de Resíduos da Agroindústria do Palmito no Vale do Ribeira. Revista Brasileira de Agroecologia, 4 (2), 2595-2598.

Silva, J. C. G. Filho, Calábria, F. A., Silva, G. C. S. \& Medeiros, D. D. (2007). Aplicação da Produção Mais Limpa em uma empresa como ferramenta de melhoria contínua. Produção, 17 (1), 109-128. https://doi.org/10.1590/S0103-65132007000100008.

Silva, M. B. \& Morais, A. S. (2008). Avaliação energética do bagaço de cana em diferentes níveis de umidade e graus de compactação. Anais do XXVIII Encontro Nacional de Engenharia de Produção, Rio de Janeiro, RJ, Brasil. 
Souza, J. W. B., Ribeiro, P. O., Moraes, A. K. C., Assis, S. M., Milhomem, T. L. Darwich, M. S. Caldas, A. M. R., Ripardo, H. S., Rolim, F. C. Neto \& Monteiro, L. S. Proposta de gerenciamento dos aspectos ambientais provenientes do processamento do palmito: Estudo de caso em uma indústria alimentícia no estado do Pará. Anais da Semana Nacional de Ciência e Tecnologia, Recife, PE, Brasil.

Rodrigues, H. S., Cruz, C. D., Macêdo, J. L. V., Resende, M. D. V. de, Lopes, R. Borém, A. (2017). Genetic variability and progeny selection of peach palm via mixed models (REML/BLUP). Acta Scientiarum Agronomy, 39 (2), 165-173. https://doi.org/10.4025/actasciagron.v39i2.32495

Vidal, T.C.M. (2014). Geração de Biogás a partir de resíduos das agroindústrias de banana e palmito pupunha. Dissertação de mestrado, Universidade Estadual do Oeste do Paraná, Cascavel, PR, Brasil.

Vojvodic, A., Komes, D., Vovk, I., Belscakcvitanivió, A \& Busic, A. (2016). Compositional evaluation of selected agro-industrial wastes as valuable sources for the recovery of complex carbohydrates. Food Research Internacional, 89, 565-673.

https://doi.org/10.1016/j.foodres.2016.07.023

Yamaguchi, S. K. F. \& Gomes, L. Netto (2016). Análise da viabilidade sustentável da instalação de uma linha de patê de palito para agregação de valor numa indústria de conserva de palmito. Revista Gestão \& Sustentabilidade Ambiental, 5 (1), 5-25. http://dx.doi.org/10.19177/rgsa.v5e120165-25. 